\title{
Google Sala De Aula: Um Relato de Experiência na Formação de Professores da Educação Básica
}

\author{
Andrey J. Guedes ${ }^{1}$, Almir O. Costa Junior ${ }^{1}$ \\ ${ }^{1}$ Licenciatura em Computação - Escola Superior de Tecnologia (EST) - Universidade do \\ Estado do Amazonas (UEA) \\ 69050-020 - Manaus - AM - Brasil \\ \{ajg.lic19,adjunior\}@uea.edu.br
}

\begin{abstract}
This paper presents an experience report on the application of a training workshop on Google Classroom for teachers of basic education in a public school in Manaus - AM. The strategy was organized in 4 stages and was carried out in the computer lab. The results found showed evidence of a better understanding of the features of the Google Classroom tool and a change in the teaching attitude regarding the adoption of this tool in the classroom.
\end{abstract}

Resumo. Este trabalho apresenta um relato de experiência sobre a aplicação de uma oficina formativa sobre o Google Sala de Aula para professores da educação básica em uma escola pública de Manaus - AM. A estratégia estava organizada em 4 etapas e foi realizada no laboratório de informática. Os resultados encontrados apresentaram evidências de um melhor entendimento sobre os recursos da ferramenta Google Sala de Aula e uma mudança na postura docente em relação a adoção desta ferramenta em sala de aula.

\section{Introdução}

As tecnologias vêm mudando cada vez mais o cotidiano do indivíduo do século XXI. Ao longo dos anos mudanças significativas foram sendo consolidadas, sejam elas em seu modo de pensar, de se comunicar e de se informar nesta sociedade transformada principalmente pelo advento das novas tecnologias digitais da informação e comunicação.

Contudo, ainda é possível verificar que diversos segmentos da sociedade ainda fazem uso de estratégias e recursos tecnológicos ultrapassados para solucionar problemas contemporâneos, como por exemplo, a educação. Muito além do ambiente escolar, professores e alunos devem se atentar para esta nova realidade tecnológica da sociedade atual. Neste sentido, a falta de suporte pedagógico e de recursos tecnológicos podem acabar desencorajando os professores na experimentação de novas metodologias inovadoras de ensino [Moran, Masetto e Behrens 2007].

Diante deste cenário, este trabalho apresenta um relato de experiência de aplicação de oficinas formativas sobre o Google Sala de Aula para professores da educação básica em uma escola pública de Manaus - AM.

Para relatar esta experiência, o artigo foi organizado como segue. A apresentação do Google Sala de aula é realizada na Seção 2. As estratégias metodológicas e os 
recursos são apresentados na Seção 3. Os resultados e as discussões são apresentados na seção 4 e por fim, as considerações finais na Seção 5.

\section{Sobre o Google Sala de Aula (Classroom)}

O Google for Education é um serviço do Google que fornece versões personalizáveis de forma independente de vários produtos do Google, usando um nome de domínio fornecido pelo cliente. Possui vários aplicativos da Web com funcionalidade semelhante às suítes de escritório tradicionais, incluindo: Gmail, Google Drive, Google Agenda, Google Documentos, Google Forms, Google Apresentação, Google Hangout, Meet e o Google sala de aula [Mendes e Amorim 2019; Google For Education 2020].

O Google Sala de Aula (Classroom) é uma plataforma que simula uma sala de aula virtual que oferece diversos recursos para que os professores e alunos possam ingressar em um ambiente de ensino-aprendizagem colaborativo e interativo. $\mathrm{O}$ ambiente pode ser acessado através do navegador Web ou aplicativos para dispositivos móveis com sistema operacional Android ou IOs [Google Classroom 2020].

Alguns estudos enfatizam que os aplicativos desenvolvidos pela Google e possíveis de ser integrados com o Google Sala de aula, permitem aos seus usuários realizar praticamente todas as atividades de comunicação, criação, edição, gravação, compartilhamento, divulgação e armazenamento de arquivos diretamente a partir da internet. Esses recursos ajudam a troca de ideias, a realização e o compartilhamento de atividades em grupos [Costa, Mandú, da Costa, Ribeiro e Couto 2019; Junior, Lisbôa e Coutinho 2011].

\section{Estratégias e Recursos Utilizados}

Nesta seção são apresentados o contexto de aplicação, os recursos tecnológicos e as estratégias metodológicas utilizadas durante a aplicação das oficinas sobre os recursos do Google Sala de Aula

\subsection{O Público-alvo e o Contexto de Aplicação}

A experiência relatada neste trabalho foi realizada com 5 professores da educação básica da Escola Estadual Altair Severiano Nunes no município de Manaus - AM. No período de realização das atividades, estes professores possuíram idade variando de 29 a 58 anos. Além disso, cabe ressaltar que estes professores são formados e lecionam nesta escola disciplinas variadas, tais como: i - Artes, ii - Ensino Religioso, iii - Ciências Naturais, iv - Educação Física e v - Matemática. Por fim, para a realização das atividades, foram utilizados alguns recursos pessoais dos professores ou disponíveis na escola, tais como: $\mathrm{i}$ - Projetor multimidia, ii - Celulares, iii - Notebooks e iv - Laboratório de informática.

\subsection{O Planejamento e Aplicação da Oficina}

De modo geral, as atividades relatadas neste trabalho estavam organizadas em 4 etapas (Figura 1). O planejamento e a condução das atividades foram desenvolvidos por um acadêmico do curso de Licenciatura em Computação sob a supervisão de um Prof. Msc. em Ensino Tecnológico. 


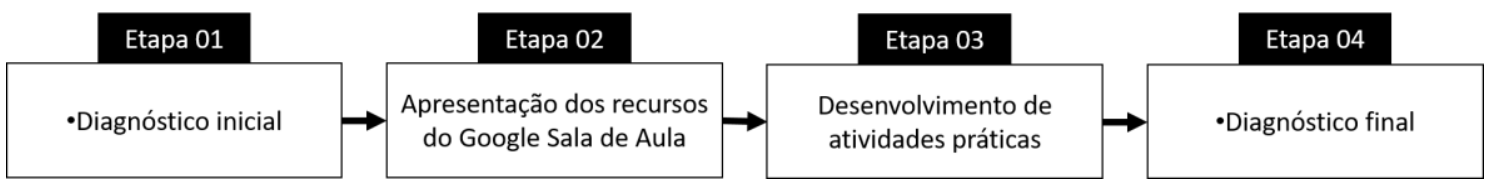

Figura 1. Visão geral da organização da oficina formativa.

\subsubsection{Etapa 1 - Aplicação do Diagnóstico Inicial}

Nesta etapa, foi proposto um diagnóstico para identificar: i - Disciplina ministrada, ii Conceitos prévios sobre Google Sala de Aula (Gráfico 1), iii - Se já haviam utilizado o Google sala de aula em atividades educacionais (Gráfico 2), iv - Se algum professor da escola onde trabalham utiliza o Google sala de aula (Gráfico 3) e v - Se eles acreditavam que as tecnologias digitais possam contribuir no processo de ensino e aprendizagem (Gráfico 4).

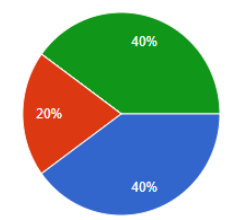

Gráfico 2. Conheciam a ferramenta.

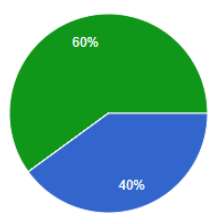

Gráfico 3. Professores que já utilizam.

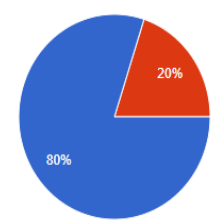

- Nunca utilize

Utilizei pouco - Utilizo muito - vilizo
Gráfico 2. Utilização prévia da ferramenta.

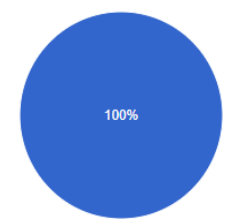

- Acredito muito

- Acredito poúc

- Desacredito parcialmente

- Desacredito totalmente

Gráfico 4. Contribuição das TICs no ensino

\subsubsection{Etapa 2 - Apresentação dos Recursos do Google Sala de Aula}

Dando continuidade as atividades da oficina, o acadêmico do curso de licenciatura em computação realizou a apresentação formal dos recursos e ferramentas disponíveis no Google sala de aula (Figura 2a). Neste sentido, foram apresentados: i - O surgimento do Google sala de aula (Figura 2b), ii - Como acessar o Google sala de aula, iii - Como criar ou entrar em uma sala, iv - Criar uma atividade e seus tipos, v - Adicionando alunos e professores e vi-Avaliando atividades.

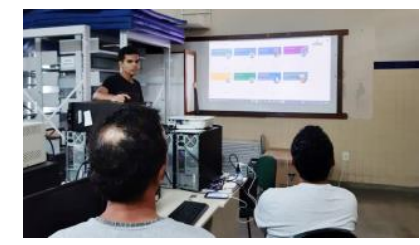

(a) Acadêmico ilustrando a ferramenta

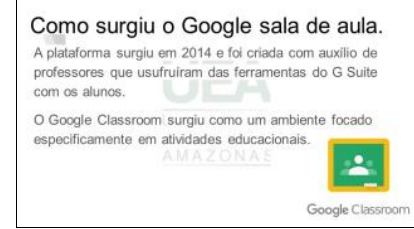

(b) Slide com a definição da ferramenta

Figura 2. Momentos da segunda etapa das oficinas.

\subsubsection{Etapa 3 - Desenvolvimento de Atividades Práticas}

Após a apresentação dos recursos do Google Sala de Aula, foi proposto aos professores a realização de atividades práticas para a fixação dos conteúdos abordados. De modo geral, a atividade desta etapa solicitava que o professores: $\mathrm{i}$ - Criassem uma turma, ii - 
Alterasse o tema, iii - Escrevesse uma mensagem de boas-vindas e iv - Criasse uma atividade do tipo dissertativa argumentativa com uma descrição e um prazo de entrega definido (Figura 3b). Esta etapa teve a duração de 1 hora. Na Figura 3a é apresentando um dos professores realizando a atividade prática.

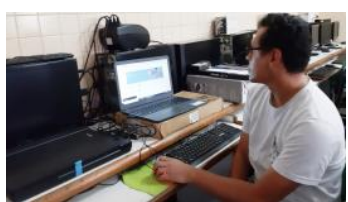

(a) Professor desenvolvendo atividade

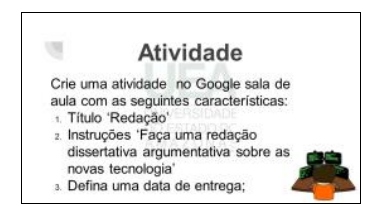

(b) Descrição de parte da atividade

Figura 3. Momentos da terceira etapa das oficinas.

\subsubsection{Etapa 4 - Diagnóstico Final}

Por fim, na última etapa da oficina foi proposto aos professores a realização de um diagnóstico final. Em essência, esse diagnóstico tinha por objetivo identificar aspectos inerentes ao processo de planejamento e aplicação após a realização da oficina. Além disso, os alunos também foram questionados em relação as suas aprendizagens e possibilidades de utilização do Google sala de aula em suas futuras atividades educacionais. Os dados contendo os resultados deste diagnóstico, são apresentados na seção 4 .

\section{Resultados e Discussões}

Após a realização da oficina, os professores foram perguntados se passariam a considerar a utilização do Google Sala de Aula em suas atividades educacionais, os 5 $(100 \%)$ professores afirmaram que Sim - Parcialmente. Quando perguntados se indicariam a ferramenta para outros professores, $3(60 \%)$ professores afirmaram que Sim - Totalmente e $2(40 \%)$ responderam Sim - Parcialmente.

Os professores foram perguntados se o instrutor da oficina foi eficiente em suas colocações, se as apresentações foram claras e organizadas, se o instrutor foi acessível e prestativo e se a avaliação foi rápida e ofereceu comentários úteis, 3 professores afirmaram Concordar Plenamente (Gráfico 5).

Por fim, quando perguntados se o objetivo da oficina foi claro e se os conteúdos do curso foram bem organizados e planejados, 3 professores afirmaram Concorda Plenamente (Gráfico 6). Ao serem questionados se a carga horária da oficina foi apropriada, 3 professores afirmaram concordar. A última pergunta solicitava que os alunos dessem sua opinião se a organização da oficina permitiu a participação de todos, 3 alunos afirmaram concordar.

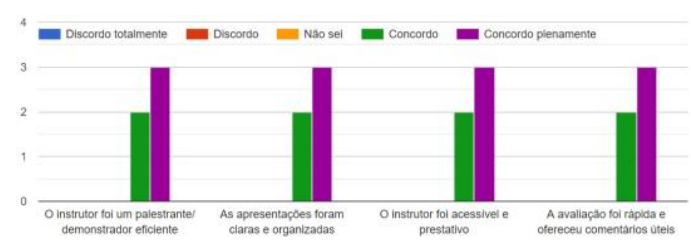

Gráfico 5. Sobre o suporte do instrutor durante as oficinas

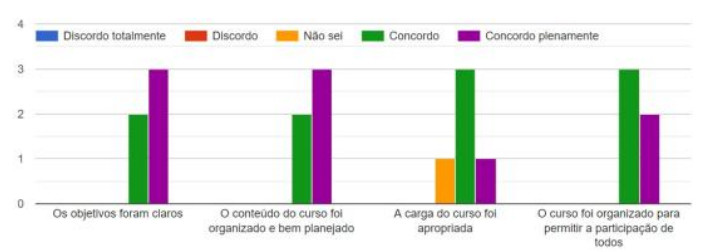

Gráfico 6. Sobre o planejamento e o objetivo da oficina

De modo geral, as atividades propostas durante as oficinas foram concretizadas dentro do espaço de tempo estabelecido para cada uma delas. Além disso, todos os participantes cumpriram com todas atividades propostas. 
É interessante destacar que em algumas das atividades, os professores participantes apresentaram níveis de dificuldades diferenciados. De certo modo, tais dificuldades podem estar associadas à falta de conhecimento ou ao não uso das ferramentas, tanto no cotidiano pessoal ou ambiente escolar. Neste sentido, foi possível observar em alguns momentos a dificuldade dos professores em utilizar o computador ou o celular para realizar as atividades, e muitas das vezes recorrendo ao auxílio do acadêmico do curso de Licenciatura em Computação.

\section{Considerações Finais}

Por fim, acreditamos que a intervenção pedagógica relatada neste trabalho apresentou uma nova visão do uso do laboratório de informática, tendo em vista que o mesmo tem sido pouco utilizado na escola. Neste sentido, a estratégia poderá será replicada com outros professores, já que foram utilizados recursos gratuitos e multiplataforma.

Além disso, a experiência foi de vital importância para a formação do acadêmico de licenciatura em computação, pois ele pôde vivenciar o dia-a-dia do ambiente escolar e desenvolver habilidades e competências intrínsecas a sua formação, tais como: definição de objetivos educacionais, planejamento pedagógico e definição de estratégias e recursos educacionais.

Como trabalho futuro, planeja-se a criação de estratégias para a formação de professores nas demais ferramentas do Google For Education, apresentando-lhes outras possibilidades de ferramentas tecnológicas que possam auxilia-los em uma disciplina especifica ou de forma interdisciplinar.

\section{Referências}

Costa, I. M., Mandú, F. N., da Costa, C. C., Ribeiro, A. F., \& Couto, D. (2019, November). Google Sala de Aula como interface de Aprendizagem Baseada em Problema (ABP) no Ensino Superior. In Anais do Workshop de Informática na Escola (Vol. 25, No. 1, p. 792).

Google for education (2020), "About Google for education”, https://edu.google.com, Maio.

Google Classroom (2020), “About Google Classroom” https://edu.google.com/intl/ptBR/products/classroom/, Junho.

Junior, J. B. B., Lisbôa, E. S., \& Coutinho, C. P. (2011). Google educacional: utilizando ferramentas web 2.0 em sala de aula. Revista Paidéi@-Revista Científica de Educação a Distância, 3(5).

Mendes, L., \& Amorim, N. (2019, November). Uso da plataforma web Google Classroom como ferramenta de apoio à metodologia Flipped Classroom: relato de aplicação no curso de Bacharelado em Sistemas de Informação. In Anais do Workshop de Informática na Escola (Vol. 25, No. 1, p. 647).

Moran, J. M., Masetto, M. T., e Behrens, M. A. (2000) Novas tecnologias e mediação pedagógica. São Paulo: Papirus. 